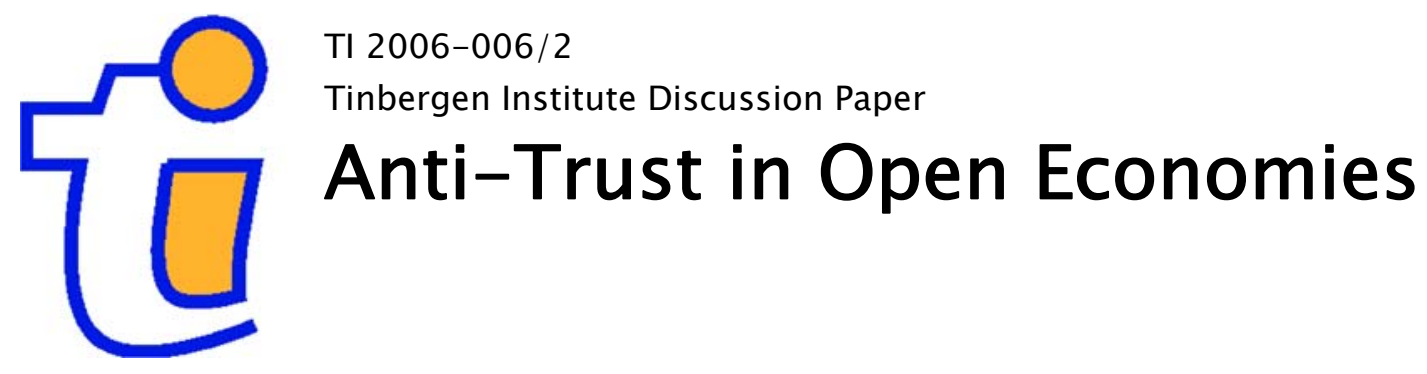

Joseph Francois ${ }^{1}$

Henrik Horn ${ }^{2}$

${ }^{\prime}$ Erasmus University Rotterdam, Tinbergen Institute, and CEPR;

2 IIES Stockholm University, The Research Institute of Industrial Economics (IUI), and CEPR. 


\section{Tinbergen Institute}

The Tinbergen Institute is the institute for economic research of the Erasmus Universiteit Rotterdam, Universiteit van Amsterdam, and Vrije Universiteit Amsterdam.

Tinbergen Institute Amsterdam

Roetersstraat 31

1018 WB Amsterdam

The Netherlands

Tel.: $\quad+31(0) 205513500$

Fax: $\quad+31(0) 205513555$

Tinbergen Institute Rotterdam

Burg. Oudlaan 50

3062 PA Rotterdam

The Netherlands

Tel.: $\quad+31(0) 104088900$

Fax: $\quad+31(0) 104089031$

Please send questions and/or remarks of nonscientific nature to driessen@tinbergen.nl.

Most TI discussion papers can be downloaded at http://www.tinbergen.nl. 


\title{
Antitrust in Open Economies
}

\author{
Joseph Francois * \\ Tinbergen Institute (Rotterdam) \& CEPR \\ Henrik Horn \\ IIES Stockholm University, \\ The Research Institute of Industrial Economics (IUI) \& CEPR
}

January 2006

We examine antitrust rules in a two county general equilibrium trade model, contrasting national and multilateral (cooperative) determination of competition policy, exploring the properties of the policy equilibrium. It is not imperfect competition, but variation in competitive stance between sectors that matters for trading partners. Beggar-thy-neighbor competition policies relate to countries' comparative advantages, and hurt the factor intensively used, or specific to, the imperfectly competitive sector. They also create a competitive advantage for export firms. FDI can be pro-competitive in this context, reducing the scope for beggar-thy-neighbor policies and reducing the gains from a multilateral competition agreement.

KEYWORDS: antitrust policy, competition policy, merger policy, trade and imperfect competition, FDI

JEL CATEGORIES: L4, F12, F3

*This paper benefits from comments at a CEPR workshop on international competition policy in Madrid and at a European Trade Study Group (ETSG) conference in Glasgow. It builds on a set of earlier papers, including Francois and Horn (1998). 


\section{Introduction}

The prospect of a multilateral agreement on antitrust, with far reaching consequences for national policy regimes, has sparked a nascent literature, including Graham and Richardson (1997), Head and Ries (1997), Horn and Levinsohn (2001), and Rysman (2001). While this literature addresses pertinent issues, it has a major weakness in that it builds on partial equilibrium frameworks. It thus implicitly assumes that the industry under study is the only industry with problems with competition, and furthermore, that this sector is sufficiently small relative to the rest of the economy to leave all factor prices unaffected any competition policy intervention. This literature is consequently in effect concerned with the implications of discretionary policy interventions, rather than with the effects of competition rules that are meant to be applied to a range of industries and circumstances. ${ }^{1}$

The reliance on a partial equilibrium framework may be appropriate when the concern is with a regulatory problem in a particular sector. But when the focus is on the establishment of a general competition policy stance, such as when formulating merger guidelines, it is clearly much less adequate. In particular, the exercise of international competition policy will typically affect broad swathes of the economies of the countries involved and is thus likely to have strong cross-sectoral ramifications. The purpose of this paper is to examine some aspects of an international competition policy agreement in a framework that takes account of such ramifications. This will allow us

\footnotetext{
${ }^{1}$ Exceptions are Auquier and Caves (1979) and Francois and Horn (1998). The general equilibrium implications of monopoly were also recognized in the early antitrust literature. The rule of proportionality, proposed in the 1930s, targeted variations in markups across sectors. (See Kahn (1935), Lerner (1934), and Robinson (1934).) In the modern antitrust literature, however, this is little more than a footnote. There is also, of course, a huge literature on the impact of market structures on trade policy in partial and general equilibrium. Traditionally, the general equilibrium branch of the theory of trade under imperfect competition emphasizes monopolistic competition, while firm-level interactions are modeled in partial equilibirum. (See Eaton and Grossman 1986 and the papers collected in Grossman 1992). While the older literature on trade and oligopoly is mostly focused on the partial equilibrium case (Markusen and Venables 1988) a recent set of papers by Neary (2003) is focused on developing trade theory with oligopoly for the general equilibrium case. While the body of work is substantial, policy space in this literature covers trade policy, and not competition policy
} 
to relate strategic and distributional aspects of competition policy to basic trade theoretic concepts like comparative advantage and terms-of-trade manipulation.

A general equilibrium approach (whether or not it addresses open economy issues) generally offers a very different perspective on competition policy compared to one based on the partial equilibrium assumptions. The conflict is no longer between the "surpluses" of consumers and producers, or of different producers, but between the real incomes of different factor owners. Even under a consumer surplus standard, optimal policy may look very different when taking into account general equilibrium ramifications of competition policy. The general equilibrium approach also yields more interesting building blocks for examining political economy aspects of competition policy, by providing richer modeling of the determinants of income distribution. A second aim of this paper is therefore to remind industrial organization analysts of the type of effects of competition policy that their traditional approach misses. While the focus here is on an international competition policy issue, several of the type of general equilibrium effects that the analysis highlights are likely to be at play also in a closed economy context. It seems to us that when addressing issues such as the appropriate general stance vis-a-vis collusion or merger, as opposed to the appropriate intervention in the case of an isolated case of collusion or a specific merger, a satisfactory analysis must inevitably take such effects into account, or it may lead to erronous conclusions.

The paper is organized as follows. Section 2 introduces a two-country, twogood model of trade with imperfect competition. Section 3 characterizes equilibrium competition policies, highlighting how the incentives for a beggarthy-neighbor type antitrust regime are related to countries' comparative advantages. In order to determine the distributional impact of competition, in Section 3 we also adopt the two basic trade models for the determination of income distributional effects of trade - the Heckscher-Ohlin-Samuelson (H-O$\mathrm{S})$ model, and the Ricardo-Viner (R-V) model. In both frameworks, factors relatively specific to competitive sectors may win from imperfect competition, and hence may be a source of support in a political equilibrium with imperfect competition. Because the strategic competition policy drives a wedge between the international price of the product and relevant marginal costs, it also creates a competitive advantage (in terms of costs) for the imper- 
fectly competitive industry. This in turn has important implications for the sustainability of strategic competition policy in a world with foreign direct investment (FDI), an issue addressed in Section 4, which shows that FDI can undermine the ability of an exporter to pursue a beggar-thy-neighbor competition policy. In this way, the workings and incentives for any international competition agreement are linked to the underlying FDI regime. Section 5 very briefly considers the impact of extra-territorial application of competition policy for the gains from an international agreement on competition policy. Section 6 summarizes the findings.

\section{The Model}

Our focus is on structural, economy-wide aspects of competition policy, rather than on discretionary intervention in particular markets. In order to capture a government's ability to affect the general degree of competition in the domestic economy, we assume that it can directly or indirectly (without cost) influence markups over marginal cost. We embed this basic feature within a two-country, two-sector general equilibrium model, where costs are determined by a general equilibrium product transformation technology. The underlying production structure is general, and consistent with, for instance, a standard $\mathrm{H}-\mathrm{O}-\mathrm{S}$ or $\mathrm{R}-\mathrm{V}$ general equilibrium framework. Our basic framework is summarized in the following list of assumptions (where subscripts denote partial derivatives and superscripts denote countries):

- There are 2 countries, indexed by $j=1,2$.

- There are 2 industries, $X$ and $Y$, each producing homogeneous products.

- Demands are identical and homothetic across countries.

- Factor markets are perfectly competitive.

- Both goods are produced under constant returns to scale. 
- There is a standard concave transformation technology between $X^{j}$ and $Y^{j}$ :

$$
Y^{j}=T^{j}\left(X^{j}\right), \quad \text { with } \quad T_{X^{j}}^{j}<0, \quad \text { and } T_{X^{j} X^{j}}^{j}<0 .
$$

- Product $X$ is sold at a price which might exceed marginal cost, in an internationally integrated market. ${ }^{2}$

- The governments control their respective domestic firms' markup levels in the $X$ sector.

- Unless otherwise noted, product $Y$ is sold in a perfectly competitive, internationally integrated market.

For the moment, we also assume governments seek to maximize national welfare, firms are purely national (they export without local presence), and there is no extra-territorial application of national competition policy. ${ }^{3}$ These last assumptions are relaxed in subsequent sections. Their implications are that exporters are beyond the reach of the government in the importing country, and that for each country we have

$$
p=\left(1+m^{j}\right) c^{j}
$$

where $c^{j}$ denotes the marginal cost faced by an oligopolist in country $j$ as defined by the underlying product transformation technology, $p$ is the price of

\footnotetext{
${ }^{2}$ Identically, we could have assumed non-discriminatory ex-factory pricing. This is a requirement of the GATT antidumping code, which treats international price discrimination as actionable and hence punishable by import duties that force equality of ex factory prices. This implies uniform ex-factory pricing across markets, even with trading costs.

${ }^{3}$ The extent to which the welfare maximization assumption is descriptive of reality can obviously be questioned. On the one hand, competition laws have a strong flavour of consumer protection. However, domestic producer interests often make their voices heard, in particular when foreign firms have been involved in alleged abuses of dominant positions, or in concentrations. For instance, the tendency to allow and even support the creation of "national champions" in many countries reveals the readiness of governments to trade-off consumer welfare against producer interests. We view the assumption of welfare maximization as a convenient middle ground between the two extremes of straightforward consumer protection, and capture by producer interests. In any event, for the purpose of this paper, other ways of weighing producer interests into country 1's objective function for competition policy would also suffice. Other possibilities are discussed briefly below in Section 3. The two last assumptions above will be relaxed in Section 4 .
} 
the product $X$, and $\left(1+m^{j}\right)$ is the domestic firms' markup over marginal costs. We can use any price as the numeraire, and find it convenient to normalize the unit cost of production for $Y$ to unity. Because it is the difference in competition between sectors that matters (see Section 3), treating the $Y$ sector as a competitive benchmark does not compromise the main thrust of our results.

We have outlined the model in a somewhat sparse manner, partly to preserve tractability. However, the structure is actually richer than it may first appear. Because we rely on a dual representation of the general equilibrium structure of the economy, we can interpret our general results with respect to a range of well-known trade models (Dixit and Norman (1980)). In addition, in the interest of relative generality, we have not explicitly modeled a particular strategic equilibrium between firms. Again, this allows us to drop down to more specific (competition) models when useful. For example, the simplest way of thinking about the model is to assume that in each country there is a single quantity-setting producer in the $X$ sector. Unchecked these firms would be in a Cournot-Nash equilibrium. However, the respective government can force its producer to behave more or less competitively. Another representation consistent with this approach involves a fixed number of firms in each country that manage to collude perfectly with the aid or enforcement of the respective government. The governments can then enforce a target level of collusion within the industry concerned, such that markups are in the range between the perfect competition and monopoly level of markup:

$$
p=\left(1-\frac{\lambda^{j}}{\epsilon}\right)^{-1} c^{j}
$$

where $\epsilon^{j}$ is the perceived demand elasticity for the sector, ${ }^{4}$ and $1 \geq \lambda^{j} \geq 0$ is an index of the effective degree of competition.

\footnotetext{
${ }^{4}$ Equation (3) also follows if we assume that the government indirectly determines markup rates through concentration policy as proxied by the number of firms in the market, provided that there are no fixed costs involved. The Cournot-Nash equilibrium value of $\lambda^{j}$ will then equal $\frac{\theta^{j}}{n^{j}}$, where $\theta^{j}$ is the quantity-based market share of the country $j$ industry producing $X$, and $n^{j}$ the number of firms. Since market share will itself be a function of the number of firms in equilibrium, $\lambda^{j}$ can be set through an appropriate industrial concentration policy. This approach has been used in several of the recent partial equilibrium studies of international aspects of competition policy referred to in the Introduction.
} 
Let us now characterize the general equilibrium of this economy. Since factor markets are assumed to be perfectly competitive, the marginal cost in terms of product $Y$ faced by an oligopolist in the $X$-sector must equal the amount of $Y$ that is sacrificed for the marginal unit of product $X$ :

$$
c^{j}=-T_{x}^{j}\left(x^{j}\right)
$$

Hence, by equation (2) and equation (4), we have

$$
p=-\left(1+m^{j}\right) T_{x}^{j}\left(x^{j}\right)
$$

Let industry output of product $X$ be $x^{j}$ in country $j$. Market clearing for product $X$ requires that world demand equals world supply, or formally that

$$
S(p)\left[p\left(x^{1}+x^{2}\right)+T^{1}\left(x^{1}\right)+T^{2}\left(x^{2}\right)\right]=p\left[x^{1}+x^{2}\right]
$$

where $S(p)$ is the budget share of product $X$ in expenditures, and the bracketed term on the left-hand side is world income expressed in terms of product $Y$. Expressions (4), (5), and (6) constitute a system of equations sufficient to determine the unknowns $p, c^{j}, x^{j}$ as functions of the two markups $m^{j}$. Henceforth $P\left(m^{1}, m^{2}\right), C^{j}\left(m^{1}, m^{2}\right)$, and $X^{j}\left(m^{1}, m^{2}\right)$ will refer to these equilibrium solutions for $p, c$, and $x$. It is straightforward to show that in equilibrium,

$$
X_{m^{j}}^{j}<0, X_{m^{j}}^{i}>0, P_{m^{j}}>0, i \neq j
$$

We next turn to the definition of comparative advantage. To this end, let $D^{j}\left(m^{1}, m^{2}\right)$ be the domestic consumption of product $X$ in country $j$. We will say that Country 1 has a comparative advantage in product $X$ in the sense that it is a net exporter of $X$ in the case where there is global perfect competition in this industry, i.e. $X^{1}(0,0)>D^{1}(0,0)$. Deviations from this equilibrium pattern can then be attributed to differences in competition, or identically to policy-induced competitive advantage. In order to simplify the discussion, we will assume that trade patterns are not reversed for any combination of markups: ${ }^{5}$

$$
X^{1}\left(m^{1}, m^{2}\right)-D^{1}\left(m^{1}, m^{2}\right)>0, \forall\left(m^{1}, m^{2}\right)
$$

\footnotetext{
${ }^{5}$ This will hold for the Nash equilibrium set of competition policies, see below. Outside the Nash equilibrium set of competition policies, we can construct cases where the direction of trade depends on markups/collusion. For example, with otherwise identical countries (and hence no traditional basis for trade in endowment or technology models of trade), differential markup policies will generate exports of $\mathrm{X}$ from the country with the lowest markup levels.
} 
We can define national welfare on the basis of identical homothetic preferences as follows:

$$
W^{j}\left(m^{1}, m^{2}\right) \equiv \frac{1}{I(P)}\left[\left(P-C^{j}\right) X^{j}+C^{j} X^{j}+T^{j}\left(X^{j}\right)\right]
$$

where $I(P)$ is the equilibrium value of the utility price index (an ideal consumer price index) for the representative consumer, defined over composite consumption good $Q .{ }^{6}$ The first term in this expression represents profit, while the second and third terms represent factor incomes.

\section{Antitrust in a Trade-Only Equilibrium}

Taking the social welfare measure in expression (9) as the government objective function, we can now characterize the properties of the policy equilibrium, with emphasis on aggregate and distributional effects of the choice of policies.

\subsection{Aggregate Effects}

The typical industrial organization analysis would view significant markups in a particular industry as a clear indication that there is likely to be a socially wasteful misallocation of resources in the industry. Once the analysis is extended to a general equilibrium framework, the perspective changes fundamentally, however. In particular, once the interplay between monopolistic practices in different sectors is taken into account, it is the difference in competition between sectors that is critical. This finding is definitely not new - it can be traced back to Kahn (1935), Lerner (1934) and Robinson (1934) - but it seems to have gone unnoticed in the modern industrial organization literature. To demonstrate this feature, assume temporarily (and

\footnotetext{
${ }^{6}$ Given homothetic preferences, it follows directly from the the properties of the social expenditure function $E(P, W)$ defined over welfare $W$ and prices $P$. It allows us to deflate nominal income values directly. The terms $E_{P}=Q$ and $E_{W}=I(P)$ follow from the definition of the national expenditure function, and its properties. For a more detailed account of duality in trade theory, see the technical annex to Dixit and Norman (1980).
} 
contrary to what has been assumed above) that there is an economy-wide markup rate $\tilde{m}^{j}$, a situation we will refer to as Lerner proportionality. In this economy, incomes for factor owners, as well as the aggregate profits, will depend on the markup. In particular, the higher is the markup, the larger is the share of GDP that accrues to profits. GDP itself will not be affected by the level of the markups, however: By our numeraire definition, the cost of producing $Y$ remains unity, though the price of $Y$ may change. We will then have income $\left(1+\tilde{m}^{j}\right) \cdot G\left(P^{0}, V^{j}\right)$ where $G$ is the GDP function defined over the competitive equilibrium price vector $P^{0}$ and the endowment vector $V^{j}$. The indirect utility price index can then also be defined with respect to the competitive equilibrium price vector $P^{0}$ and our (symmetric) markups: $I(P)=\left(1+\tilde{m}^{j}\right) \cdot I\left(P^{0}\right)$. The real income is then

$$
W^{j}(\cdot)=\frac{G\left(P^{0}, V\right)}{I\left(P^{0}\right)}
$$

which as can be seen is independent of the markup level. Hence: ${ }^{7}$

Proposition 1 With Lerner proportionality, the impact of imperfect competition is to redistribute income from factor owners to recipients of profits. Aggregate welfare is unaffected.

Note that Proposition 1 can be seen as providing some support for the use of a consumer surplus standard in competition policy. If problems of imperfect competition are pervasive in the economy, this may not be of primary concern from an aggregate welfare point of view, but could still be very harmful to consumers, by lowering their real incomes and hence having important distributional effects.

For the rest of the paper we focus on situations where there are asymmetries between sectors such that the markups differ. Consider the case where the

\footnotetext{
${ }^{7}$ It may help to imagine a process where the government imposes identical degrees of competition, as measured by markups, through a policy of concentration. Individual oligopolists then try to raise prices by reducing output. In an economy-wide setting, this leads to falling factor prices. With falling marginal cost, oligopolists boost output, restoring full employment at lower factor prices. In this sense, an economy-wide equivalence in the degree of competition is like an economywide VAT or output tax.
} 
$Y$ sector is inherently competitive, but where markups can be encouraged (through mergers or collusion) in the $X$ sector. The impact on real national income (deflated by the price of utility) of a marginal increase in the markup rate $m$ in sector $X$ is

$$
W_{m^{j}}^{j}=\frac{m^{j} X_{m^{j}}^{j}}{I(P)}+\frac{X^{j}-D^{j}}{I(P)} P_{m^{j}}
$$

The first term in this expression is negative. It represents the loss of profits on existing sales as we reduce output further to boost the markup rate itself. The sign of the second term depends on whether the country is a net importer or exporter of product $X$, and is positive if and only if the country exports the product. It represents terms-of-trade gains made at the expense of the net importer. The net exporter will have an incentive to cartelize the sector since

$$
W_{m^{j}}^{j}(0,0)=\frac{X^{j}(0,0)-D^{j}(0,0)}{I(P)} P_{m^{j}}>0
$$

Hence, the net exporter of product $X$ has an incentive to deviate from any perfectly competitive equilibrium.

Proposition 2 Absent an international antitrust agreement, national welfare maximization implies that the $X$ importer will enforce marginal cost pricing among its $X$ firms, and the $X$ exporter will allow for positive markups by its $X$ firms.

By focusing on the Nash equilibrium competition policy and its relationship to comparative advantage, Proposition 2 means that we avoid potential indeterminacy about the effects of foreign competition on domestic competition policy in partial equilibrium.

Obviously, from a world point of view the Nash equilibrium is sub-optimal, as can be seen from

$$
\frac{d}{d m^{1}}\left[W^{1}\left(m^{1}, m^{2}\right)+W^{2}\left(m^{1}, m^{2}\right)\right]=\frac{m^{1}}{I(P)} X_{m^{1}}^{1}+\frac{m^{2}}{I(P)} X_{m^{1}}^{2}
$$

which is negative for $m^{2}$ sufficiently small. Consequently: 
Proposition 3 An international agreement on antitrust policy could increase world welfare. However, to improve welfare for both countries, side payments are necessary.

Proposition 3 suggests two separate reasons why attempts are underway to bring a competition policy agreement into the WTO, rather than let it stand by itself. First, our Country 1 prefers the non-cooperative equilibrium to the situation where marginal cost pricing is enforced globally. Hence, in order for both parties to accept an agreement on competition policy it is necessary that Country 1 receives some form of side payment. The wide-ranging structure of the WTO agreements is likely to offer ample opportunities for such concessions. Note, however, that this is an argument for why the competition policy agreement may need the trade agreement to be politically viable, rather than vice versa. The second reason follows from the next Proposition:

Proposition 4 An international antitrust agreement would increase trade.

The strategic competition policy induces both countries to shift production toward their respective import sectors, and trade in both products is reduced (albeit not eliminated). The reduction in trade follows directly from price increases on the part of the Country 1 producers. At the same time, we know that exports will not be eliminated. Even if it were possible to choose $m^{1}>0$ such that trade ceased to exist, it would not be optimal, since at such a value of $m^{1}$,

$$
W_{m^{1}}^{1}=\frac{m^{1} C^{1}}{I(P)} X_{m^{1}}^{1}<0
$$

In terms of trade volumes, a trade and a competition policy agreement would thus be complementary. Therefore, considering the fact that the WTO is an organization with a pronounced "more trade is always better" attitude, the attempts to bring competition policy into the WTO are not surprising.

The equilibrium described by Propositions 2 - 4 can be summarized using Figures 1 and 2. In the figures, the Country 1 and Country 2 transformation frontiers as defined in equation (1) are mapped relative to origins $O^{1}$ and $O^{2}$. World production will be defined by point $a$ while consumption is at 
point $b$. Perfect competition in both countries is represented by a tangency of the two production possibility frontiers. This is so because at point $b$ we have equality between the marginal rates of transformation, prices, and marginal valuation in consumption. As prices and preferences are assumed identical across countries, consumption is along the diagonal from $O^{1}$ to $O^{2}$. International trade is then the re-allocation of quantities needed to let both countries consume at point $b$, given the global production point $a$. As such, the import quantities (the trade vector) are shown as $m_{x}^{2}$ and $m_{y}^{1}$. The efficiency frontier $\mathrm{BB}$ is derived by tracing point $O^{1}$ as we move the Country 1 production frontier along the Country 2 production frontier, maintaining tangency.

In contrast to the competitive equilibrium in Figure 1, with the strategic competition policy equilibrium in Figure 2 production instead occurs at point $a$ with non-marginal cost pricing by one country and marginal-cost (i.e. competitive) pricing by the other. Consumption takes place at a point $b$ at goods prices given by a slope for the line $a b$ that is higher, for good $X$, relative to the corresponding line in Figure 1. The positive markup in the home country is reflected in the non-tangency of price with the Country 1 frontier. Proposition 2 is reflected by the fact that point $O^{1}$ is below the global efficiency envelope without tangency.

\subsection{Strategic Competition Policy and Competitive Ad- vantage}

We now turn to the policy interaction between the governments. To see the incentive for country $j$ to intervene, consider the impact of an increase in the markup in its domestic sector on real factor incomes, as given by the last terms of expression (9). In general we have equation (14).

$$
\frac{d}{d m^{j}}\left[\frac{C^{j} X^{j}+T^{j}\left(X^{j}\right)}{I(P)}\right]=-\frac{C^{j} X^{j}+T^{j}\left(X^{j}\right)}{I(P)^{2}} I_{P} P_{m^{j}}+\frac{C_{m^{j}}^{j}}{I(P)} X_{m^{j}}^{j}<0
$$

On the right-hand side, the first term in brackets represents the relative price effects (the price of $X$ changes relative to that of $Y$ ), while the second term relates to the drop in factor income following from reduced factor demand 
(as firms try to constrain output). The second term flags a reduction in the cost of producing $X$ and implies a drop in aggregate factor incomes. We can therefore also conclude the following:

Proposition 5 A strategic competition policy not only increases profits of domestic firms by permitting larger markups, but also tends to enhance the apparent competitive advantage of these firms by lowering their marginal costs.

Note that Proposition 5 relates to a pure general equilibrium phenomenon. When an exporting country is large enough to affect international prices, a generally slack competition policy (or one that actively encourages exercise of market power) in this country will lead to lowered demand for factors of production, and this will in turn reduce their rewards. ${ }^{8}$

The strategic competition policy is similar in its effect to those of a strategic trade policy in a Cournot setting, in that it lowers the marginal costs for exporters and hence confers to them a cost advantage. However, in the case of the strategic trade policy, the lower costs are meant to capture market shares, whereas here with the strategic competition policy the exporting country loses market share. It is more like an optimal trade policy in the Bertrand case, which as shown by Eaton and Grossman (1986) often is a tax, even though here the gain comes only through the reduced competition between domestic firms. Hence, the competition policy here is not "strategic" in the sense of altering the competitive position of domestic firms vis-a-vis foreign competitors, but in the sense of affecting the competition between domestic firms.

\subsection{The Distributional Effects of Strategic Competi- tion Policies}

In standard industrial organization analysis, cartelization has positive externalities for outside firms in the industry. However, here the firms from the

\footnotetext{
${ }^{8}$ Though without formalization, Norman (1996) makes a similar observation.
} 
net importing country will not be able to profit from the cartelization, since their government continues to enforce marginal cost pricing. Therefore, since all income is factor income in this country, these factor owners as a group lose from the other country's competition policy. Hence, when we draw a line between (collective) factor owners and firm owners in the two countries, the only income group that gains in the aggregate from the cartelization is the owners of firms in the $\mathrm{X}$ industry in Country 1.

But while factor owners as a group in each of the countries lose from cartelization, it is still possible that certain factor owners gain. In order to determine possible winners and losers, and thus the likely sources of support for an international competition policy agreement, we must add further structure to the production technologies. We consider two standard trade models commonly employed to examine issues of income distribution.

First, assume that the underlying transformation technology in equation (1) is the reduced form of a H-O-S economy. With positive markups in the $X$ sector, output in this sector is constrained relative to the other sector (assuming full employment of both factors). It is this reduction in output, and hence in input demands, that forces factor incomes down relative to final goods prices, and makes profits possible. At the same time, the $Y$ sector will not employ factors in the same proportion in which they are released by the $X$ sector. Hence, from the well-known relationship between goods prices and factor incomes in the Heckscher-Ohlin model (aka Stolper-Samuelson theorem), the fall in the relative value of $C^{j}$ (i.e. marginal cost) will also involve a fall in income for the $X$ intensive factor greater than the reduction in $C^{j}$. Designating $\Omega^{X, 1}$ as the equilibrium income of the factor used intensively in $X$ production in Country 1:

$$
P_{m^{1}}>0>C_{m^{1}}^{1}>\Omega_{m^{1}}^{X, 1}
$$

The fact that price increases relative to marginal cost follows from the markup policy itself, and costs have to fall, as we have seen above. The third inequality follows from the basic Stolper-Samuelson theorem. In fact, the $X$ intensive factor will suffer the most, in real income terms, from cartelization of the $X$ sector. The impact on the other factor will be ambiguous, since its income may fall relative to $P$ (depending on markup levels), even as it rises 
relative to the other good $Y$ :

$$
P_{m^{1}}>0>C_{m^{1}}^{1} \text { and } P_{m^{1}} \gtrless \Omega_{m^{1}}^{Y, 1}>0
$$

The imposition of a markup in the $X$ sector implies that the consumer price of $X$ in terms of $Y$ increases, whereas relative marginal costs fall. With competitive pricing in factor markets, and with constant returns to scale, we know from the Stolper-Samuelson theorem that there will be a reduction in the reward of the factor that is intensively used in this sector in terms of both products, and an increase in the reward of the other factor relative to both marginal costs. However, since the markup increases the price of $X$ relative the marginal cost of $X$, it is not clear that the $Y$-intensive factor will actually gain in terms of the sector $X$ price. This factor sees its income rise vis-a-vis the price of good $Y$, though it may rise or fall relative to good $X$. Consequently, the welfare effect is unclear with regard to this factor owner. This is directly analogous to the impact of a production tax in a H-O-S model. ${ }^{9}$

Consider next the alternative assumption that equation (1) reflects a $\mathrm{R}-\mathrm{V}$ transformation technology. Hence, we have a factor specific to each sector, and a factor that is fully mobile between sectors. Again, we know that markups are accomplished by constraining output in the $X$ sector. This reduced demand for inputs will depress demand for the mobile factor and the $X$-specific factor, so that both lose unambiguously as we shift from competition to a positive markup. Again, there is a direct analogue to the impact of a production tax in the R-V model. In the $Y$ sector, the $Y$-specific factor will experience rising productivity (as the mobile factor moves into the sector), and rising income in terms of the numeraire $Y$. However, because the price of $X$ rises as well, the net effect is ambiguous. ${ }^{10}$

We can summarize the factor income effects as follows:

\footnotetext{
${ }^{9}$ There are empirical issues raised by the factor market effects we have flagged here that go beyond this paper, but that merit exploration. For example, we should expect relative factor prices to vary systematically with market structure. In addition, in rigid wage economies like those in continental Western Europe, we may expect variations along the employment margin (i.e. unemployment) rather than the wage margin, again as a function of variations in general degrees of competition.

${ }^{10} \mathrm{We}$ could of course assume that the specific factor captures profits.
} 
Proposition 6 The benefits from the strategic competition policy are focused on a specific income group - owners of firms in the imperfectly competitive sector in the country imposing a markup. The only factors that do not lose unambiguously from such a policy are those that are relatively specific (in a $H-O-S$ or $R-V$ sense) to the competitive sector.

Hence, the support for an international agreement which prevents this type of behavior should stem from all factor owners except possibly for these latter groups, and the resistance would hinge on the ability of owners to form a coalition with the factor that is specific or intensively used in the competitive sector of the economy. ${ }^{11}$

\section{Antitrust with Both Trade and FDI}

The results above may seem to provide a compelling economic rationale for an international antitrust agreement, such as the one currently under negotiation in the WTO. But there are several reasons not to jump to such a conclusion. First, as a practical matter, little is known about the empirical magnitude of the problem such an agreement is supposed to solve. But there are also more basic reasons for scepticism, as we will see. First, the analysis above assumes the absence of foreign direct investment (FDI). Once FDI is brought into the picture, the case for an international agreement becomes much weaker, as long as it is rendered "national treatment". Second, there are also unilateral actions that countries can take to mitigate the problem. In particular, as argued in the ensuing section, extra-territorial application of national antitrust laws can serve such a role.

\footnotetext{
${ }^{11} \mathrm{~A}$ logical approach beyond the scope of this paper is to introduce a formal political economy structure and embark on a detailed analytical treatment of political economy equilibrium competition policies in general equilibrium, starting with the basic winners and losers identified here. Combined with the political decision process (majority voting, coalition building, etc.) this will lead to the sustained policy set. Depending on the power of the beneficiaries of the strategic competition policy, in a politically determined equilibrium the net importer government may also support a domestic cartel, even though this is unambiguously bad for overall national welfare. Alternatively, with rent sharing between inside labour and firm owners, it might be possible to build a coalition of labor that includes the "losing" factor.
} 


\subsection{Introducing Foreign Direct Investment}

While a standard assumption in trade theory (and even more so in industrial organization) is that firms serve foreign markets through exports without any local presence, in practice firms often serve foreign markets through local production. As we will argue, the possibility for firms to undertake FDI may have significant ramifications for the welfare-enhancing potential of a competition policy agreement. Indeed, in the policy debate there is parallel to the discussion concerning the desirability of an international agreement on competition policy, there is a similar (and politically much more charged) discussion about an international investment agreement. These issues are intertwined, circling partly around the question of whether these agreements are likely to increase or reduce trade, and whether agreements on competition policy should and/or FDI should be brought into the WTO Agreement.

In order to examine the impact of FDI on the need for an international agreement on competition policy formally, we return to the model laid out in Section 2, but now relax our assumption regarding local presence, and assume that FDI means that firms can produce wherever they find it to be profitable. Firms in the imperfectly competition industry can thus divide their production between the two countries in any way they want. Firms come under the jurisdiction of each country in which they have some production. Importantly, the host country is assumed to give identical treatment to foreign producers in terms of, for instance, access to factors of production at the same prices as faced by domestic firms (there are thus no special taxes or input requirement imposed on foreign production), and that it enforces the same competition rules with regard to foreign producers for the production they undertake in the host country, as it applies to domestically owned firms. There are indeed already some WTO rules in the Trade-Related Investment Measures (TRIMS) Agreement that require such "national treatment", even though these rules are incomplete and relatively untested in

WTO jurisprudence. The EU has a relatively recent set of rules following this principle, while the US, a much older customs union, has a long history of enforcing such rules internally under the Interstate Commerce clause of the US Constitution. In addition to TRIMS, in a WTO context we also have rules on imports and the WTO agreement on services (the GATS or General Agreement on Trade in Services) as further examples on non-discrimination 
provisions of international (and interstate) commercial rules.

It is instructive to conduct a thought experiment introducing the opportunity for FDI in the trade-only type of equilibrium we examined before, and summarized in Figure 2. In this equilibrium, firms located in Country 1 have a competitive advantage following from lax competition enforcement. Country 2 firms will hence find it profitable to shift production to Country 1, provided that they receive national treatment there. Assuming that the investing firms repatriate their earnings, this will shift profits to Country 2. At the same time, the optimal markup for Country 1 among its firms clearly falls because profit, including profit gained at the expense of domestic consumers, is now partially captured by foreigners. In terms of equation (11), the terms-of-trade gain that followed from the partial monopolization is reduced. Country 2, on the other hand, will not find any reason to change its policy of marginal cost pricing. It takes advantage of the lower production costs in Country 1, induced by the partial monopolization of the industry, and it tends to gain both on account of the profit shifting, as well as the improved terms-of-trade.

How far will this reallocation process go if left unchecked? Country 2 firms will have incentive to shift production to Country 1 as long as there is any difference in production costs between the two economies, or until all production of $X$ occurs in Country 1 . This reallocation will continue either until all production of $X$ occurs in Country 1, or until Country 1 ceases to allow/enforce prices above marginal costs. In the latter case, the production equilibrium would be exactly the same as in the case of a globally welfare maximizing competition policy agreement.

Formally, note that in the presence of foreign production, the welfare of Country 1 is

$$
V^{1}\left(m^{1}, m^{2}\right)=\frac{1}{I(P)}\left[\left(P-C^{1}\right) X^{1}+C^{1}\left(X^{1}+Z\right)+T^{1}\left(X^{1}+Z\right)\right]
$$

where $X^{1}$ now refers to production of product $X$ by Country 1 firms, and $Z\left(m^{1}, m^{2}\right)$ is production of $X$ by Country 2 firms in Country 1 . At what level of foreign production will Country 1 enforce marginal cost pricing in the Nash equilibrium? Differentiating with respect to $m^{1}$ and evaluating at 


$$
m^{1}=m^{2}=0: \quad V_{1}^{1}(0,0)=\frac{X^{1}-D^{1}}{I(P)} P_{m^{1}}+\frac{Z}{I(P)} C_{m^{1}}
$$

The first term is positive as before. The second term is negative. Country 2 firms will hence shift production to Country 1 until their joint production is such as to make the right-hand side of this expression equal to zero. When this holds, there are no incentives for foreign producers to either increase or reduce their production in Country 1.

The pro-competitive effect of FDI identified here contrasts with that normally portrayed in the trade and the industrial organization literature. It is not the increased competition in a Cournot-Nash equilibrium due to an increase in the number of firms, nor is it the undercutting by external firms of the cartel price. Instead, FDI reduces the optimal degree of concentration for Country 1 for two reasons: first, it enables foreign firms to take a share of the surplus initially created through concentration for the domestic country; and second, the FDI increases marginal costs in the domestic industry, reducing competitive advantage. Hence, at the margin, we have less surplus created by a given markup. Basically, FDI acts to arbitrage away cost advantages created by the beggar-thy-neighbor competition policy. ${ }^{12}$

The findings can be summarized as follows:

Proposition 7 Inward FDI may induce Country 1 to enforce marginal cost pricing, as long as it provides national treatment to foreign production, thus removing the global efficiency gains from an international agreement on competition policy. ${ }^{13}$

One reason why the policy discussion on the Multilateral Agreement on Investment proposed by the OECD has been so charged is that this agreement has been seen as providing national treatment protection (or even stronger

\footnotetext{
${ }^{12}$ We should note that if we were to introduce unions or rigid wages in our general equilibrium setup, factor costs may not adjust fully and the incentive for FDI may therefore be reduced.

${ }^{13} \mathrm{~A}$ tax on the earnings of foreign-owned plants could be used to limit this mechanism.
} 
protection) to investing firms, without imposing any constraints on their behavior. Hence, some have suggested that an international investment agreement must be complemented with an agreement on competition policy. The analysis above offers a rather different perspective. Proposition 7 suggests that (within our model) an agreement on national treatment may weaken the incentives for countries to pursue a beggar-thy-neighbor antitrust policy. Actually, the marginal cost pricing equilibrium achieved through FDI is exactly the same as the equilibrium that would arise if marginal cost pricing were enforced through an international agreement. To see this, note that the marginal cost pricing Nash equilibrium with FDI is characterized by the following expressions:

$$
\begin{gathered}
p=-T_{x}^{j}\left(x^{j}\right) \quad j=1,2 \\
S(p)\left[p\left(x^{1}+x^{2}\right)+c^{1} z+T^{1}\left(x^{1}+z\right)+T^{2}\left(x^{2}\right)\right]=p\left(x^{1}+z+x^{2}\right) \\
\left(x^{1}-d^{1}\right) E_{P} P_{m^{1}}+z c_{m^{1}}^{1}=0 \\
D^{1}=S(p)\left[p x^{1}+c^{1} z+T^{1}\left(x^{1}+z\right)\right]
\end{gathered}
$$

where $p=c^{1}$. Equation (19) defines marginal cost pricing, equation (20) is our market clearing condition, equation (21) follows from equation (18) and relates the profit-shifting effect against terms-of-trade gains, while equation (22) defines home demand. Equations (19) and (20) define a sub-system that yield equilibrium prices and output $P$ and $X^{j}$. With identical demands, these are identical to those in the competitive equilibrium with trade only.

This finding can be illustrated graphically by again using Figure 1, assuming that we have started from the equilibrium in Figure 2. This new equilibrium imposes the conditions in equations (19) through (22). Given equations (19) and (20), FDI moves trade to the same level as under a competitive tradeonly equilibrium (identical to the case originally illustrated in the figure). Hence, we have a tangency in the figure with both production possibility frontiers, and a trade vector identical to a competitive non-FDI trade vector. The only difference is that in the case of FDI, in Country 2 firm production is now split into the domestic production $X^{1}$ and the foreign production $Z$. However, since there is marginal cost pricing, there are no profits in this sector, and the ownership of firms in the sector is immaterial outside any transition process.

Country 1 loses from the FDI, since it suffers both a terms of trade loss and a loss of income through shifting of profits to Country 2 (assuming that 
firms repatriate their profits), and Country 2 correspondingly gains. The reason why there are unambiguous losses to Country 1 is that the investing firms do not bring with them either technology, or any productive resources. Consequently, Country 1 has an incentive to deny firms from Country 2 equal access to domestic resources, or to remove their incentives to invest by enforcing marginal cost pricing. ${ }^{14}$

Proposition 8 In the absence of side payments, Country 1 will oppose both an international agreement on antitrust, as well as an international agreement on investment that would enforce national treatment of FDI.

\subsection{Extra-Territorial Application of National Compe- tition Policy}

Clearly, one reason why the country with net exports of product $X$ manages to pursue a strategic competition policy is the fact that the importing country has no jurisdiction over the exporting firms, by our assumption about extra-territoriality. Hence, an obvious solution from the point of view of the importing country would be to apply its competition policy extraterritorially. This is exactly the strategy followed in recent years by the European Commission vis-a-vis foreign mergers. Exporting firms in Country 1 would then come under two jurisdictions, and it would here seem reasonable to assume that the more stringent of the two applied. Therefore, Country 2 would enforce marginal cost pricing both at home and abroad, and the extra-territorial application of Country 2's competition policy would thus lead to a globally efficient outcome. This could also be accomplished by requiring marginal cost pricing. Ironically, anti-dumping laws encourage the behavior that extra-territorial competition policy would oppose. These laws effectively encourage price discrimination when it leads to higher prices in export markets. In this sense, they are anti-competitive. ${ }^{15}$

\footnotetext{
${ }^{14}$ Note that firm interaction/collusion in product markets may mean they are also able to erect entry barriers against FDI. See for example Campa et al (1998).

${ }^{15}$ See Head and Ries (1997) for a discussion of extraterritoriality. Note that while in the present model, the government of Country 2 faces the correct incentives from a global welfare viewpoint, this may conceal some drawbacks associated with extra-territoriality.
} 
Proposition 9 A system of extra-territorial application of national competition policies would substitute for an international agreement on these policies.

\section{Summary}

The purpose of this paper has been to demonstrate the need to broaden the perspective in competition policy analysis. The currently prevailing approach in industrial organization theory, of implicitly restricting the analysis to the study of a discretionary intervention in a small distorted sector in an otherwise perfectly competitive economy that is closed to the rest of the world, is too limited for the analysis of many current policy issues. To highlight the difference an open economy, general equilibrium approach may make, we have pointed to certain basic aspects of antitrust in a very simple two-country, two-sector trade model in which countries can choose a general competitive stance. This has allowed us to highlight the role of relative opportunity cost, through the economy-wide interactions between goods and factor markets, for the design of national competition policies in a trade context.

The general equilibrium approach yields a significantly different perspective on antitrust than does the standard IO framework:

1. It is the difference in the degree to which different sectors diverge from perfect competition that matters. The markup in a particular sector is hence not a valid predictor of misallocation of resources.

2. The rents created through imperfect competition will partly end up with factor owners through the interaction of factor and product markets. This "rent dissipation" does not require factor owners to be

In the present model, "maximal competition" is globally desirable. However, if we relax the assumptions of the present model, then a system of over-lapping jurisdictions may tend to lead toward too much competition, from a world welfare viewpoint. For example, in the presence of economies of scale, the issue may look different. In such a case it might be desirable to allow for some exploitation of market power, the private benefits of which may be unevenly distributed internationally, in order to enable exploitation of returns to scale. 
cartelized, as often maintained in the IO literature. As a consequence, indices of competition that rely on costs, such as Lerner indices, exaggerate the absolute price reduction that enforcement of perfect competition would entail. As competition is increased, not only will the price tend to fall, but marginal cost will also tend to increase.

3. The consumer-producer dichotomy may be misleading. What matters to consumers is their real income. Exactly how different consumers are affected depends on the underlying production structure. Certain consumers may lose from lack of competition both because they face higher prices, and because their incomes fall. Other consumers may benefit enough on the latter account to gain overall.

With regard to the more specific issue of the scope for an international agreement to curb beggar-thy-neighbor competition policies, we have observed:

4. Countries that are net exporters in the sectors that are more easily cartelized have incentives to pursue beggar-thy-neighbor competition policies.

5. There is a certain political logic to the fact that there are attempts to bring such a competition policy agreement into a structure like the WTO. This is, in part, because such an agreement would enhance trade. This is also because a competition policy agreement may require side payments, and a trade agreement, like the WTO or regional schemes, offers plenty of scope for members to trade off gains under one agreement with losses under another agreement. There is reason to believe that support for such an agreement could come from a wide spectrum of factor owners in both exporting and importing countries.

The discussion has also suggested that the gains from an international competition policy agreement may be limited due to certain other legal regimes:

6. If FDI is permitted and is provided national treatment, investment can be expected to respond to the competitive advantages created by national competition policies, and to undermine the scope for a competition policy agreement. 
7. Extraterritorial application of competition laws may effectively prevent countries from pursuing beggar-thy-neighbor policies.

Finally, much of the development in trade policy analysis during the last 25 years has come from the importation of tools and insights from the industrial organization literature. We hope that this paper contributes to convincing industrial organization researcher economists that it is time to make the exchange of ideas more balanced. 


\section{References}

Auquier, A.A. and R.E. Caves. (1979). "Monopolistic Export Industries, Trade Taxes, and Optimal Competition Policy," The Economic Journal 89 (September), 559-581.

Campa, J., S. Donnenfeld and S. Weber (1998). "Market Structure and Foreign Direct Investment." Review of International Economics 6(3): 361380.

Dixit, A. and V. Norman (1980). Theory of International Trade, Cambridge University Press: Cambridge.

Eaton, J. and Grossman. G.M, 1986. "Optimal Trade and Industrial Policy under Oligopoly." The Quarterly Journal of Economics, 383-406 Vol. 101 (2) pp. 383-406. MIT Press.

Francois, J. and H. Horn (1988). "Competition Policy in Open Economies." Tinbergen Institute discussion paper 98-092/2.

Graham, E.G. and D. Richardson, Competition Policies for the Global Economy, Institute for International Economics Policy Analyses in International Economics No. 51, November, 1997.

Grossman, G., ed., mperfect Competition and International Trade, MIT Press: Cambridge MA, 1992.

Head, K. and J. Ries (1997). "International Mergers and Welfare under Decentralized Competition Policy." Canadian Journal of Economics; 30(4), 1104-23.

Horn, H. and J. Levinsohn (2001). "Merger Policies and Trade Liberalization." Economic Journal, 111 (April), 244-273.

Kahn, R.F. (1935). "Some Notes on Ideal Output." Economic Journal 45 (March), 1-35. 
Lerner, A.P. (1934). "The Concept of Monopoly and the Measurement of Monopoly Power." Review of Economic Studies 1 (June), 157-175.

Markusen, J. and T. Venables (1988). "Trade Policy with Increasing Returns and Imperfect Competition," Journal of International Economics 24(1988): 299-316.

Neary, J.P. (2003). "Globalization and Market Structure." Journal of the European Economic Association 1(2-3, June): 245-271.

Norman, V. (1996). "A Small Open Economy Perspective on International Competition Policy." Presented at the Oslo Competition Conference, Norwegian Competition Authority, June.

Robinson, J. (1934). The Economics of Imperfect Competition. London, MacMillan.

Rysman, M. (2001). "Competition Policy as Strategic Trade." Industry Studies Program Discussion Paper No 46, Department of Economics, Boston University. 


\section{Annex: derivation of equation (11)}

This annex explains the derivation of equation (11), which is the basis for subsequent welfare analytics within the paper. The welfare expression (9)

$$
W^{j}\left(m^{1}, m^{2}\right)=\frac{1}{I(P)}\left[\left(P-C^{j}\right) X^{j}+C^{j} X^{j}+T^{j}\left(X^{j}\right)\right]
$$

can be simplified as follows:

$$
W^{j}\left(m^{1}, m^{2}\right)=\frac{1}{I(P)}\left[(P) X^{j}+T^{j}\left(X^{j}\right)\right]
$$

The derivatives with respect to the markup $m^{j}$ are

$$
W_{m^{j}}^{j}\left(m^{1}, m^{2}\right)=A+B
$$

where

$$
A=\frac{\left[P X_{m^{j}}^{j}+T_{X^{j}} X_{m^{j}}^{j}+P_{m^{j}} X^{j}\right]}{I(P)}
$$

and

$$
B=-\frac{I_{P} P_{m^{j}}\left[P X^{j}+T^{j}\right]}{I(P)^{2}}
$$

Using equation (4) we can rewrite $A$, as

$$
A=\frac{\left[m^{j} X_{m^{j}}^{j}+P_{m^{j}} X^{j}\right]}{I(P)}
$$

And by Shepard's Lemma we can express demand $D$ on its dual form

$$
D=I_{P} W^{j}=I_{P}\left[P X^{j}+T^{j}\right]
$$

implying that

$$
B=-\frac{D P_{m^{j}}}{I(P)}
$$

Combining these expression, we have equation (11):

$$
W_{m^{j}}^{j}=\frac{m^{j} X^{j}}{I(P)}+\frac{X^{j}-D^{j}}{I(P)} P_{m^{j}}
$$




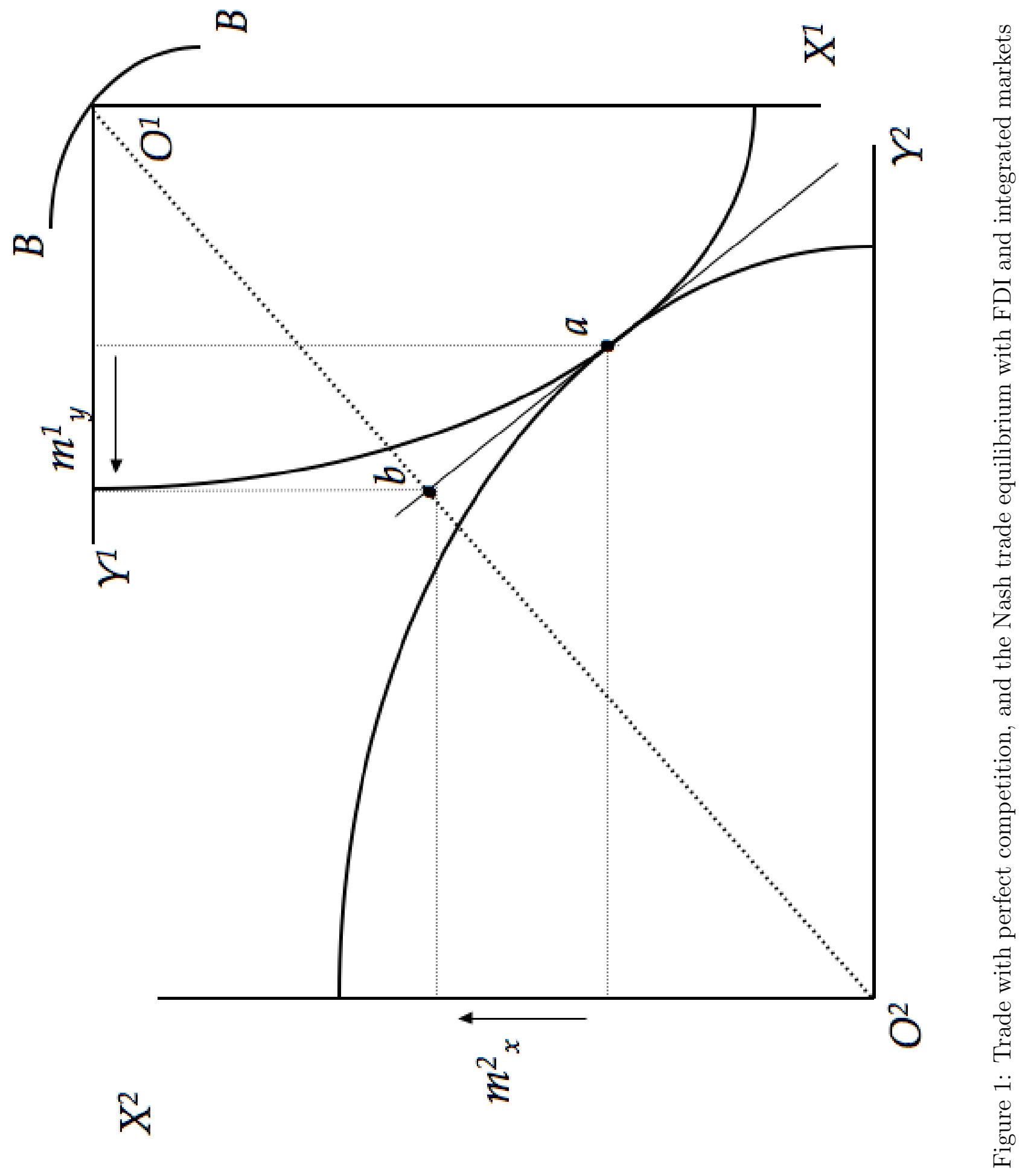




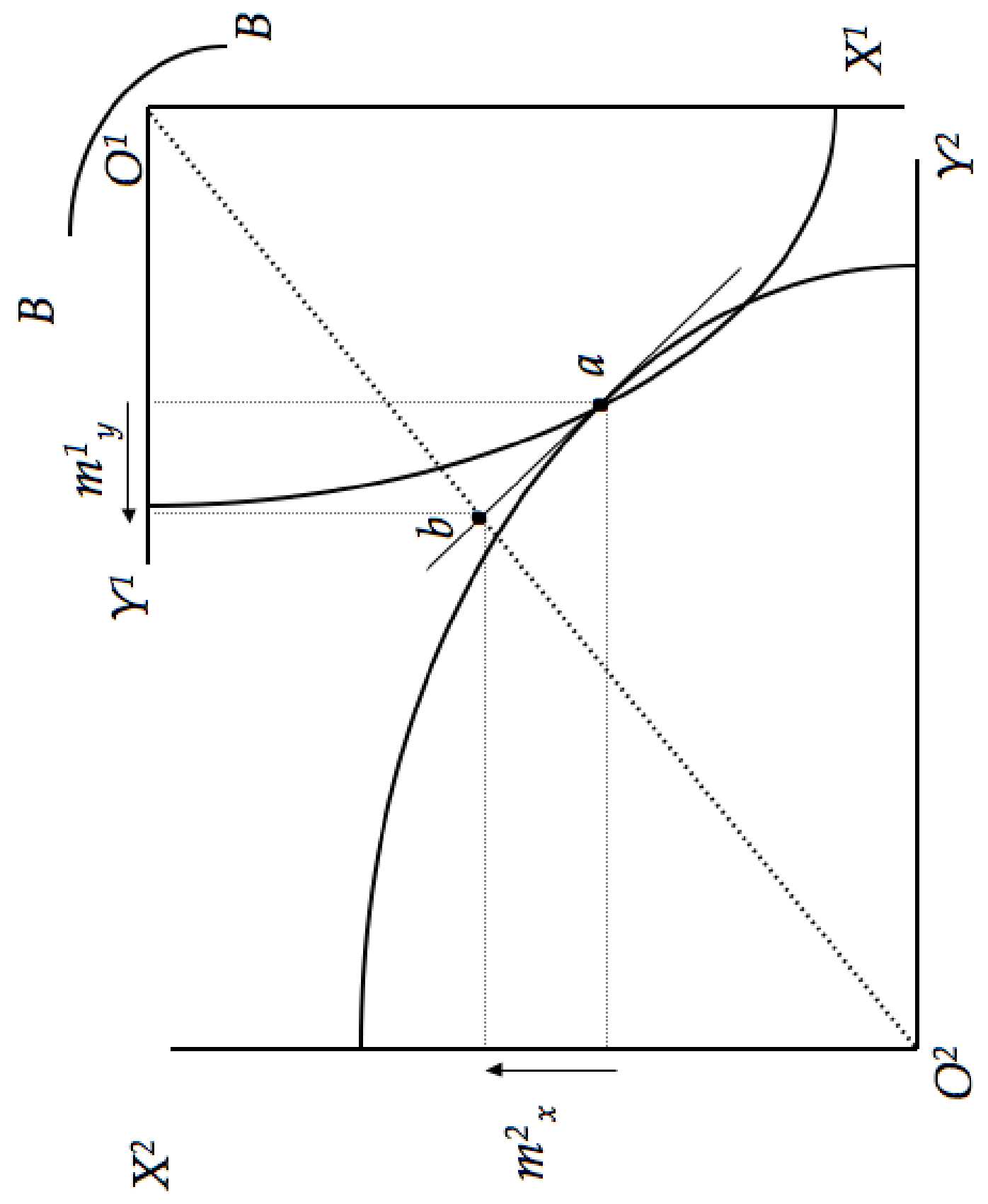

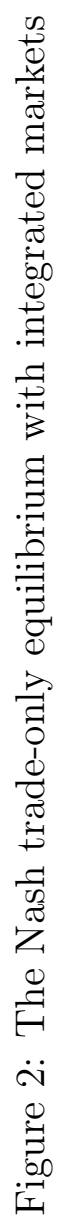

